\title{
Study of College Teaching Archive Management from the Perspective of Systems Engineering
}

\author{
Min $\mathrm{Hu}^{1, \mathrm{a}}$ \\ ${ }^{1}$ School of Politics, Southwest University for Nationalities, Chengdu 610041, China; \\ a skbhumin2006@sina.com
}

Keywords: college teaching archives, systems engineering, archive management, RFID.

\begin{abstract}
The entity files and electronic files of teaching archives are manually managed, thus a few problems are caused when the teaching archives are collected, retrieved or used. In order to solve the problems, the systems engineering approach is applied to study the college-level teaching archive (CTA) management in the paper, and a new CTA management mode, which integrates teachers, students, administrative staffs, database and RFID technology as a whole to manage the CTA production process, is presented for the purposes of promoting the automation of the CTA management.
\end{abstract}

\section{Introduction}

Systems engineering is an interdisciplinary approach to design, implementation and evaluation that holds the key to the successful development of complex human-made systems. Systems engineering tools are strategies, procedures, and techniques that aid in performing systems engineering on a project or product. The purpose of these tools varies from database management, graphical browsing, simulation, and reasoning, to document production. Systems engineering techniques are used in complex projects: spacecraft design, computer chip design, robotics, software integration, and bridge building [1]. The question arises as to whether the systems engineering techniques can be used in the college-level teaching archive (CTA) management or not. The teaching archives are valuable teaching file materials which are produced directly during teaching management, teaching practice, and teaching research activities. They have types of text, chart, video, and disk, and play an important role in improving teaching quality. But the CTA management faces many problems : 1) no specialized storage rooms for teaching archives; 2) no professional for managing teaching archives, at present as a part-time job taken by college secretaries; 3) not being supported by database technology, the entity files and electronic files are managed manually, this causes problems for collecting, retrieving or using the teaching archives; 4) lack of systems engineering management mode, managing teaching archives effectively. In order to solve the problems, it is necessary for the CTA management to be studied from the perspective of systems engineering. The CTA management is a project which has properties of systems engineering. The college-level teaching archives are not simple added-sum of all teaching archives from the teaching units (departments/schools of a university), they have system-level functions. In recent years, many researchers have studied the CTA management, but their results now available in the literature have not mentioned the CTA management mode with properties of systems engineering, and have not integrated teachers, students, administrative staffs, backstage database server, and RFID technology as a whole. This makes it hard to collect valuable teaching archives and produce the desirable effect of teaching archives. In order to improve the limitation of the current CTA management studies, the CTA management mode with properties of systems engineering is studied in the paper.

\section{Systems Engineering}

Firstly the definition of what a system is in the field of systems engineering is given, and then the concept of systems engineering is briefly outlined. 
Definition of a system. A system is a construct or collection of different elements that together produce results not obtainable by the elements alone. The elements, or parts, can include people, hardware, software, facilities, policies, and documents; that is, all things required to produce systems-level results. The results include system level qualities, properties, characteristics, functions, behavior and performance. The value added by the system as a whole, beyond that contributed independently by the parts, is primarily created by the relationship among the parts [2].

Systems Engineering. Systems engineering is a robust approach to the design, creation, and operation of systems. In simple terms, the approach consists of identification and quantification of system goals, creation of alternative system design concepts, performance of design trades, selection and implementation of the best design, verification that the design is properly built and integrated, and post-implementation assessment of how well the system meets the goals [3].

From the perspective of systems engineering, the CTA management system can integrate teachers, students, administrative staffs, entity teaching archive files, electronic teaching archive files, database server and RFID technology as a whole. It is clear that the CTA management possesses the properties of systems engineering.

\section{The College Teaching Archive Management Mode Based on Systems Engineering}

The CTA management is a project with properties of systems engineering, therefore, the systems engineering approach is used to analyze the teaching archive classification, teaching archive staff structure and CTA management scheme.

The teaching archive classification based on systems engineering. The teaching archive management has become complex increasingly due to the implementation of credit system in China. But the teaching archives can be classified into types as follows.

Teaching Type. Curriculum syllabus, teaching plan tables, test questions database, approval tables of test paper, standard answer sheets of test papers, lists of student's grade, record charts of test room, exam results analysis tables, teacher's teaching manuals, video courses, multimedia coursewares, materials of bilingual teaching courses, typical teaching archives, important notes of teaching preparation.

Graduation Project Type. Summary sheets of graduation projects and grades, graduation project management regulations, graduation designs, graduation papers, graduation reports and typical experience materials of advisors.

Experiment and Practice Type. Social practice plans, social practice summary materials and commendation materials; practice teaching regulations, practice teaching materials, practice base construction and running materials, practice reports, performance evaluation tables, practice summary materials, typical practice teaching materials, practice lists for students and advisors, practice lists for the student's groups and practice planning lists.

Discipline Type. Application materials of undergraduate bachelor's degree, materials of curriculum planning and construction, materials of major training schemes, application materials of teaching reform.

Teaching Archive Staff Structure Based on Systems Engineering. Teaching archive production has connection with teachers, students, school-level administrative staffs and college-level administrative staffs, and their interactions are though the production process of teaching archives, thus they are managing staffs of the teaching archives according to systems engineering. The students maintain their information modules, course-selection modules and teaching-evaluation modules. Teachers support their information modules and the modules dealing with teaching type of archives, graduation project type of archives, experiment and practice type of archives and discipline type of archives. Once per semester, The school-level administrative staffs file teaching type of archives, graduation project type of archives, experiment and practice type of archives and discipline type of archives. The college-level administrative staffs file teaching archives from every school once per semester too. 
The CTA Management Scheme Based on Systems Engineering. On the basis of systems engineering, the collection and processing functions of college-level teaching archive (CTA) management system are distributed to every school-level teaching archive management system, and the archive information is concentrated to CTA management system from all school-level teaching archive (STA ) management systems. The CTA management system is shown in Fig. 1. The STA management system is depicted in Fig. 2, the student's subsystem includes information module, course-selection module and teaching- evaluation module, and teacher's subsystem has information module and the module dealing with teaching archives.

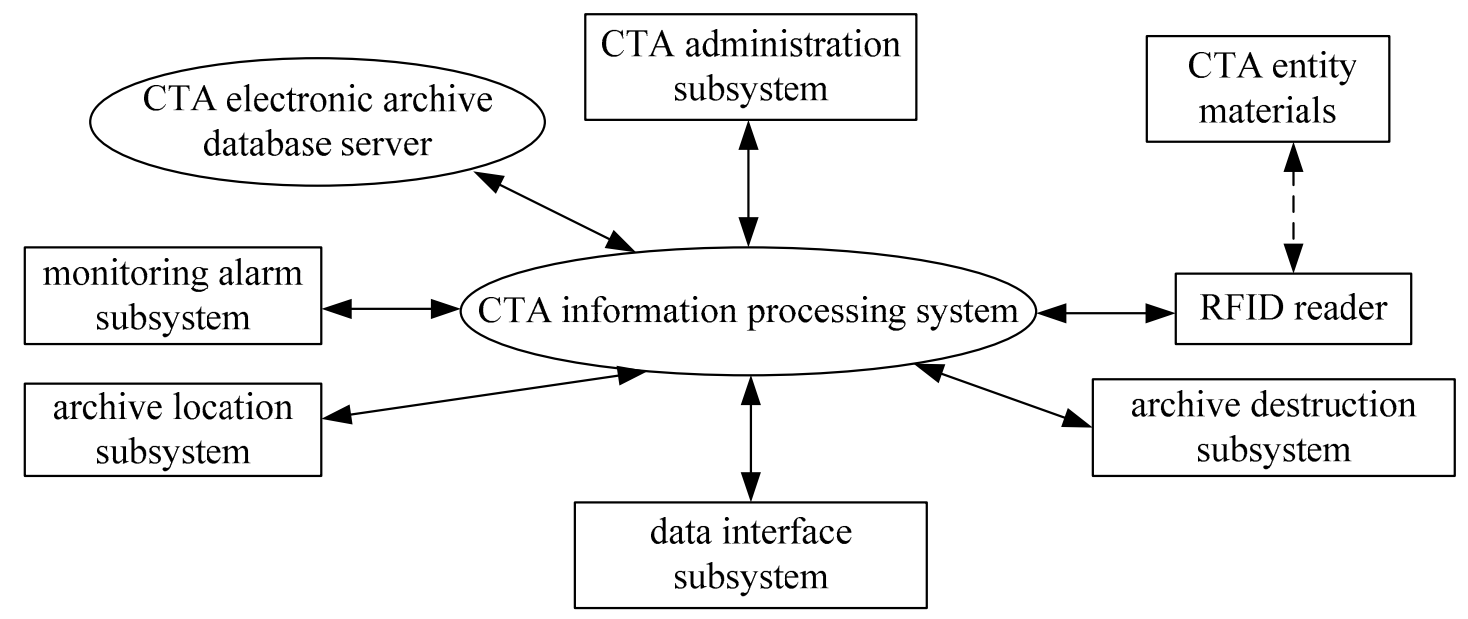

Fig. 1 College-level teaching archive management system

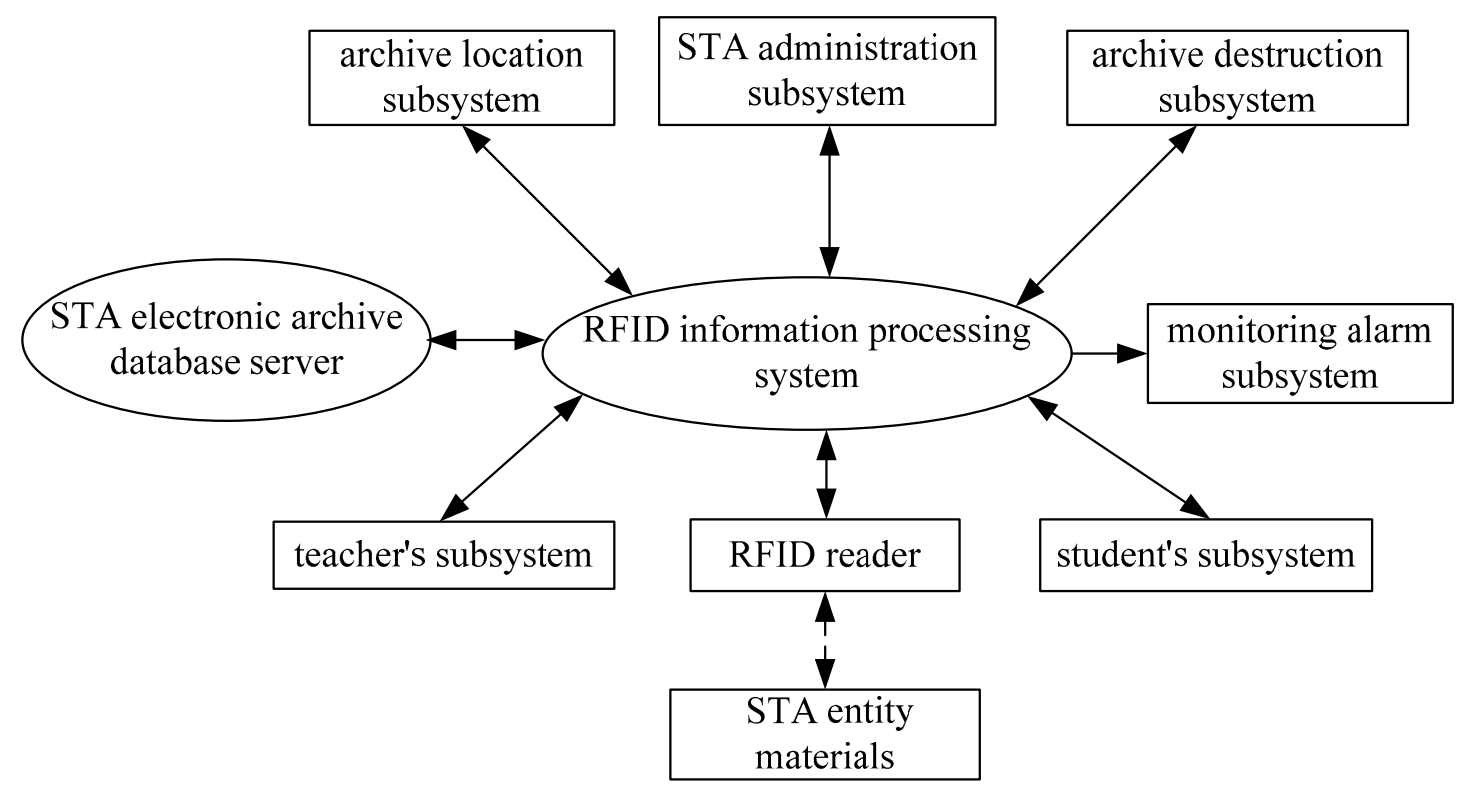

Fig. 2 School-level teaching archive management system

The Scheme of College-level Teaching Archive Management System. The CTA management system consists of CTA electronic archive database server, CTA information processing system, RFID (radio-frequency identification) subsystem, archive query subsystem, archive destruction subsystem, archive location subsystem, monitoring alarm subsystem, data interface subsystem and CTA administration subsystem. Through the data interface subsystem, the archive information from all STA management systems is filed once per semester by college-level administrative staffs.

The Scheme of School-level Teaching Archive Management Subsystem. The STA management system is made up of STA electronic archive database server, RFID information 
processing system, RFID subsystem, archive query subsystem, archive destruction subsystem, archive location subsystem, monitoring alarm subsystem, and STA administration subsystem. The filed information is sent to data interface subsystem through the STA administration subsystem by the school-level administrative staffs.

The data interface subsystem in Fig. 1 can be connected to all STA administration subsystems with internet, thus the complete teaching archive management system is formed. The distributed database technology, RFID technology and internet technology has become an integral part of the teaching archive management system. The teachers, students and administrative staffs are integrated as a whole to effectively manage the CTA production process through information technologies such as database technology, RFID technology and internet technology. This makes the teaching archives be ease of use. It is clear that the teaching archive management is not a task only related to the administrative staffs. The teachers, students and administrative staffs are responsible for their own assigned work to make the teaching archive management go with the CTA production process, to make the teaching archive management have dynamic characteristics, and to make the teaching archives improve teaching quality, advance young teachers' teaching skills and support the evaluation of disciplines.

\section{Summary}

The college teaching archive management based on systems engineering is studied in the paper, and a new CTA management mode which possesses properties of systems engineering is presented. The new mode requires the collection and processing functions of CTA management system are distributed to school-level teaching archive management systems, and the filed archive information of all STA management systems is concentrated to the CTA management system. The teachers, students and administrative staffs are integrated as a whole to effectively manage the CTA production process, the teaching archive management is not a task only related to the administrative staffs as before. We hope that the teaching archives can improve teaching quality, advance young teachers' teaching skills and support the evaluation of disciplines.

\section{Acknowledgment}

This work was supported in part by the Fundamental Research Funds for the Central Universities ( 2015SZYQN17).

\section{References}

[1] Information on http://en.wikipedia.org/wiki/Systems_engineering\#cite_note-7.

[2] Information on http://www.incose.org/practice/fellowsconsensus.aspx.

[3] NASA Systems Engineering Handbook. NASA. 1995. SP-610S. 